\title{
Rozwój filmowych adaptacji komiksów - „kino superbohaterskie” jako gatunek
}

\author{
KRZYSZTOF CZYŻAK \\ Uniwersytet im. Adama Mickiewicza w Poznaniu
}

\begin{abstract}
Aвstract. Czyżak Krzysztof, Rozwój filmowych adaptacji komiksów - „kino superbohaterskie” jako gatunek [The evolution of comic book adaptations - 'superhero movie' as a genre]. „Images” vol. XXVIII, no. 37. Poznań 2020. Adam Mickiewicz University Press. Pp. 338-348. ISSN 1731-450X. DOI 10.14746/i.2020.37.20.

This article is an attempt to consider superhero movies as a developing genre of popular cinema. The theory is based on Rick Altman's "Semantic/Syntactic/Pragmatic" approach to genre. It tries to capture features of superhero blockbusters and their main themes - the most distinctive trait of this genre, according to the author of the text, is supposed to be the relationship between an individual, their "power" and society. The text is both an extension of and a counter-proposal to conclusions made by Tomasz Żaglewski in Kinowe uniwersum superbohaterów.
\end{abstract}

KEYWORDS: comic book movie, movie genre, Marvel Studios, superhero, superhero movie

Gdy zajrzymy na strony główne serwisów streamingowych, mamy dużą szansę, że wśród proponowanych nowych filmów znajdziemy przynajmniej jedną adaptację komiksowej opowieści o superbohaterach - najpewniej skupioną na postaciach stworzonych $\mathrm{w}$ wydawnictwie Marvela bądź DC Comics. Obdarzeni mocami herosi na dobre zadomowili się w medium kina (oraz formach serialowych) i jak na razie nic nie

[1] Metoda produkcyjna studia Marvela polega na kreowaniu relatywnie spójnej metanarracji $\mathrm{i}$ tworzeniu połączonego uniwersum $\mathrm{z}$ wielu różnych tytułów skupionych na superbohaterach. Od Iron Mana (2008) powstało ponad dwadzieścia filmów, których akcja rozgrywa się w tym samym fikcyjnym świecie. Ta strategia kopiowana była przez studio 2oth Century Fox (które próbowało stworzyć narracyjny organizm $\mathrm{z}$ różnych tytułów powiązanych $\mathrm{z}$ grupą postaci Marvela, do której ma prawa - X-Men), Warner Bros (montujące wciąż własny odpowiednik uniwersum Marvela $\mathrm{z}$ bohaterami wydawnictwa DC), Sony Pictures (usiłujące zbudować serię na postaciach orbitujących w komiksach wokół Spidermana), a także Universal Studios, które jako jedyne nie próbowało oprzeć swojego metatekstu na superbohaterach, lecz zapowiadało realizację wskazuje na to, by mieli szybko zniknąć z tych przestrzeni. Zjawisko „kina superbohaterskiego" stanowi bardzo ważny element współczesnej konstelacji wysokobudżetowych filmów rozrywkowych, a ponadto solidne podstawy może mieć teza, że metoda produkcyjna studia Marvela znacząco wpłynęła na funkcjonowanie innych studiów, takich jak Warner Bros., 2oth Century Fox czy Universal Studios[1]. Warto więc przyjrzeć się bliżej tego typu produkcjom - choć agresywnie wdzierają się w sferę audiowizualnej popkultury, nie otrzymały one wielu filmoznawczych opracowań. W ramach tego tekstu chciałbym dotknąć jednego z zagadnień towarzyszących kinu superbohaterskiemu. Zamierzam podjąć próbę odpowiedzi na pytanie: czy można określić je mianem rozwijającego się w tym momencie gatunku filmowego? Tym samym chciałbym dokonać swoistej kategoryzacji tego działu kina.

\section{Kategorie komiksu filmowego,} kina komiksowego i filmu graficznego

W polskiej praktyce filmoznawczej przy omawianiu filmów traktujących o przygodach superbohaterów najczęściej pojawiają się dwa określenia: film komiksowy i komiks filmowy. 
Terminy te albo dotyczą adaptacji komiksu, albo związane są z bardzo umownie pojmowaną „komiksową wrażliwością” - i mają inne znaczenia w zależności od opinii oraz intencji badacza z nich korzystającego. Pogłębionego przeglądu pojęć dotykających sfery kina komiksowego i produkcji opowiadających o superbohaterach dokonuje Tomasz Żaglewski w Kinowym uniwersum superbohaterów[2], pierwszej (na polskim gruncie) całościowej próbie omówienia i skategoryzowania współczesnego filmu superbohaterskiego oraz jego aktualnych perspektyw. Autor tej pozycji proponuje własną terminologię - wychodzi od koncepcji Jerzego Szyłaka i jego podziału na film komiksowy oraz komiks filmowy, a także dodaje do tego termin „kino graficzne”, zaczerpnięty z badań M. Keitha Bookera. Komiks filmowy - uznany przez Żaglewskiego za potoczną formułę - miałby odnosić się do filmów niebędących adaptacjami, ale intuicyjnie wiązanych $z$,komiksowością" (a przynajmniej z pewnymi stereotypami na jej temat). Kino komiksowe wiązałoby się z luźnymi adaptacjami opowieści obrazkowych, na przykład takimi, które czerpałyby z kompilacji motywów i tematów komiksów (tak funkcjonuje większość produkcji superbohaterskich - choćby seria filmów o Iron Manie pobiera wątki z wielu różnych historii obrazkowych $\mathrm{z}$ udziałem tego bohatera i tworzy z nich nową opowieść[3]). Filmy graficzne związane byłyby zaś $\mathrm{z}$ adaptacjami wiernie przekładającymi fabułę i - co najważniejsze - estetykę danego dzieła komiksowego (na przykład 300 Zacka Snydera czy Sin City Roberta Rodrigueza)[4].

Trudno przeczyć temu, że określenia „film komiksowy” i „komiks filmowy” dość mocno osadziły się w polskiej literaturze naukowej. Warto jednak zauważyć, że narodziły się przed okresem wielkich przemian w obrębie kina komiksowego. W ostatnich latach nastąpiła rewolucja $\mathrm{w}$ tej sferze produkcji rozrywkowych - znacząco zwiększyła się liczba tytułów skupionych na postaciach superbohaterów, a ich formuły oraz relacje między poszczególnymi utworami uległy większemu skompliko- waniu. W obliczu niegasnącej popularności filmów opowiadających o odzianych w trykoty herosach[5] może się pojawić pytanie: czy nadal jest to nazewnictwo dostatecznie precyzyjne?[6]. W wyżej wspomnianym Kinowym uniwersum superbohaterów autor dokonuje interesującej analizy produkcji opowiadających o przygodach superherosów jako niszy ewoluującej w kierunku większych struktur uniwersalnych - i jest to droga analizy jak najbardziej słuszna, gdyż to właśnie łączenie wszelakich produkcji komiksowych w jedną, relatywnie

„mrocznego uniwersum” z udziałem klasycznych potworów. Możemy przypuszczać, że klapa finansowa Mumii (2017) Alexa Kurtzmana pogrzebała te plany. Warto jeszcze dodać, że metoda Marvela zakłada także swego rodzaju „dobudówki” - powstały także krótkometrażowe produkcje (stanowiące formy promocji w Internecie lub dodatków na DVD/Blu-Ray) oraz seriale, które rozszerzają uniwersum o nowe wątki, dopowiedzenia istniejących (ich status ontologiczny często jednak jest niepewny, bowiem to filmy z głównej serii stanowią „kanon” i nie odnoszą się do istnienia elementów seriali - choć same seriale odnoszą się do filmów).

[2] T. Żaglewski, Komiks filmowy - gatunek, którego (wciąz) nie ma?, [w:] Kinowe uniwersum superbohaterów, Warszawa 2017, s. 15-34.

[3] Komiksy z bohaterami Marvela $\mathrm{z}$ reguły tworzą bowiem relatywnie ciągłą narrację od lat sześćdziesiątych i trudno byłoby zrealizować na ich podstawie spójną i zamkniętą adaptację.

[4] Ibidem, s. 26-31.

[5] O tej ciągłej popularności może świadczyć fakt, że czwarta część Avengers pobiła rekord przedsprzedaży biletów, należący wcześniej między innymi do innego popkulturowego giganta: serii Gwiezdne wojny, a także - co ważniejsze do innych produkcji o tematyce superbohaterskiej: Avengers: Endgame Breaks All-Time Pre-Sale Ticket Record on Atom Tickets", <https:// www.thewrap.com/avengers-endgame-breaks-all-time-pre-sale-ticket-record-on-atom-tickets/>, dostęp: 14.04.2019.

[6] Warto przywołać tu również fakt, że w klasycznych publikacjach zagranicznych (na przykład u Bordwella, Leitcha czy Davida Hughesa) również tradycyjnie wykorzystuje się termin „comic book movie” (za: D. Jeffries, Comic Book Film Style, Austin 2017, s. 8). 
spójną metanarrację, można uznać za źródło fenomenu produkcji ze studia Marvela (lidera w dziedzinie adaptacji komiksu, za którym podążyły inne wytwórnie posiadające prawa autorskie do adaptowania opowieści o konkretnych postaciach Marvela/DC na ekran). Tomasz Żaglewski odstawia jednak na bok problem kina superbohaterskiego jako odrębnego gatunku, uznając je przede wszystkim za część zbioru adaptacji komiksów. Uważam, że produkcje skupione na zamaskowanych mścicielach mają na tyle wyraziste punkty wspólne, że zasługują na osobną kategorię. Proponuję nie tyle rozważyć ich miejsce $\mathrm{w}$ przestrzeni filmu rozrywkowego, ile podjąć problem tematyki superbohaterskiej jako osobnej formuły gatunkowej.

Choć termin "kino graficzne” wydaje się bardzo użyteczny przy omawianiu ekranizacji powieści graficznych, to jednak „film komiksowy", szczególnie jako zamiennik filmu superbohaterskiego, może budzić wątpliwości. Oczywiście ma szansę funkcjonować $\mathrm{w}$ formie zaproponowanej przez Żaglewskiego jako oznaczenie genezy danych produkcji adaptacji komiksów, które luźno czerpią ze swoich pierwowzorów. Sądzę jednak, że nie wystarczy to do kategoryzowania adaptacji komiksowych jako konkretnego „typu kina”. Jako że medium komiksu oferuje bardzo zróżnicowane środki wyrazu, konwencje i estetyki (malarskie kadry Alexa Rossa[7] nijak się mają do uproszczonej kreski Marjane Satrapi[8]), samo pojęcie „komiksowy” może okazać się

[7] Zob. M. Waid, A. Ross, Kingdom Come Przyjdź królestwo, przeł. M. Drewnowski, Warszawa 2005.

[8] Zob. M. Satrapi, Persepolis, przeł. W. Nowicki, Warszawa 2015. Oczywiście truizmem jest twierdzenie, że komiks oferuje różnorodne stylistyki i narracje, jednakże właśnie to stanowi w mojej opinii argument, który osłabia wartość terminu „komiksowy” (tak samo jak określenie „filmowy”, przywołuje ono różne skojarzenia wśród odbiorców i powinno być raczej potocznym/umownym wyróżnikiem). zbyt szerokie i nieprecyzyjne, by mogło odnosić się do równie różnorodnych adaptacji. Nawet jeśli weźmiemy pod uwagę popularne superprodukcje - takie jak Logan (2017, reż. James Mangold), Asterix kontra Cezar (1999, reż. Claude Zidi) czy Valerian: miasto tysiaca planet (2017, Luc Besson) - będziemy mieli do czynienia $\mathrm{z}$ innymi typami opowieści. W mojej opinii słowo „komiksowy” nie ma wystarczającego ładunku znaczeniowego, o ile nie zaznaczamy jego umowności czy nie wykorzystujemy go przede wszystkim do określenia genologicznego źródła wspomnianych produkcji. Każda z wymienionych wyżej pozycji wydaje się czerpać z zupełnie innych konwencji. Postapokaliptyczny/westernowy Logan stawia na ponury brutalizm i nie odnosi się w wyraźny sposób do środków wyrazu znanych z komiksu, Asterix kontra Cezar próbuje emulować estetykę oryginału za pomocą konwencji kreskówkowej (i jednak bliższy się wydaje dynamice slapstickowej kreskówki, niż komiksu), natomiast Valerian mógłby zostać uznany za typowe, pulpowe kino science fiction. Poza wspólnym medium, z którego pochodzą teksty źródłowe, nie łączy ich zbyt wiele.

Uważam jednocześnie, że spośród adaptacji komiksów można wydzielić filmy superbohaterskie jako odrębną formułę gatunkową; niezależnie od tego, czy uczestniczą one w budowie większej, wieloczęściowej narracji, czy też stanowią odrębną całość (a i takie produkcje powstają w ostatnich latach - warto wspomnieć choćby animowane produkcje, jak Wielka szóstka czy Iniemamocni 2). Sądzę, że można znaleźć pewne cechy wspólne zarówno w konwencjach formalnych owych produkcji, jak i w poruszanych przez nie wątkach. Rzecz jasna, propozycja wydzielenia „kina superbohaterskiego" z kategorii filmu komiksowego może być uznana za dyskusyjną albo nieefektywną - wydaje mi się jednak, że z takim rozdziałem zyskałoby i samo medium komiksu, które byłoby dzięki temu rzadziej wiązane $\mathrm{z}$ jednym motywem popkulturowym (warto pamiętać o tym, że tematyka superbohaterska 
nie zawłaszcza całego medium i oferuje ono bardzo zróżnicowane formuły, bo w jego obrębie temat „zamaskowanego obrońcy” można uznać za - po prostu - jeden $\mathrm{z}$ funkcjonujących gatunków) oraz produkcje superbohaterskie (które mogłyby zyskać tym samym bardziej konkretną formułę opisową). Filmowe odpowiedniki odzianych w peleryny i zbroje mścicieli nie muszą mieć ścisłego związku z estetyką komiksową czy konkretnymi tytułami - nie muszą odnosić się do medium, poza czerpaniem wątków $z$ oferowanych przez nie opowieści (wątki te mogą zaś znaleźć odpowiednią realizację $\mathrm{w}$ różnych mediach[9]).

Być może warto byłoby wyodrębnić kino superbohaterskie spośród innych adaptacji komiksów, gdyż łączy je coś więcej niż pochodzenie ich tekstów źródłowych z konkretnego medium. Tym samym oddzielilibyśmy od Supermana (1978, reż. Richard Donner), Avengers (2012, reż. Joss Whedon) czy X-Men (200o, reż. Bryan Singer) produkcje takie jak na przykład wspomniany wcześniej Asterix kontra Cezar czy Surogaci (2009, reż. Jonathan Mostow). $\mathrm{Z}$ drugiej strony - w ramy kina superbohaterskiego mogłyby wejść także filmy, które nie bazują na żadnych konkretnych odpowiednikach komiksowych: bardziej konwencjonalni Power Rangers (2017, reż. Dean Israelite) czy Iniemamocni (2004, reż. Brad Bird) lub pastisze, parodie i dekonstrukcje formuły, takie jak Hancock (2008, reż. Peter Berg), Super (2010, reż. James Gunn) czy przeznaczone dla młodszych widzów Sky High (2005, reż. Mike Mitchell). Definicje kategorii "gatunku” są niejednolite, a ich wyznaczniki mogą być różnorodne. Postaram się zatem uargumentować gatunkowość kina superbohaterskiego na podstawie teorii Ricka Altmana.

\section{Kino superbohaterskie w ujęciu Ricka Altmana}

Zanim jednak przejdę do omówienia wyróżników formuły superbohaterskiej z perspektywy semantyczno-syntaktyczno-pragmatycznej[10], wspomnę też o czterech obszarach funkcjono-
[9] David Hyman podaje za Williamem W. Savagem Jr.: „Comic books could carry heroes beyond the limits of possibility imposed by radio (sounds without pictures and thus without depth or significant personification) and film (sounds with pictures, but constrained by technology). Radio, short on data, gave the consumer's imagination too much latitude, while film, rife with data, refused to give it enough. Comic books, however accidentally, managed to split the difference. They could show whatever the artist could draw, their lines and colors directing imagination, their balloon-held texts defining the time and space. Comic book artists and writers could produce that which could be conceived, which was more than the creators of motion pictures and radio program could claim" (D. Hyman. Revision and the Superhero Genre, New York 2017, s. 11) [„komiksy mogły wynieść superbohaterów poza granice nakładane przez radio (dźwięki bez obrazów, a więc bez głębi i konkretnego ucieleśnienia) i film (dźwięki i obrazy, ale ograniczone przez technologię). Radio, nie przekazując wymaganych danych, dawało wyobraźni odbiorcy zbyt wiele, natomiast film, bogaty w dane, odmawiał dostarczenia wystarczającej ich ilości. Komiksy natomiast - przypadkiem - umożliwiały znalezienie złotego środka. Mogły przekazać wszystko, co artysta był w stanie narysować, poprzez charakterystyczne linie i kolory koncentrujące wyobraźnię odbiorcy; poprzez teksty w dymkach określające czas i przestrzeń. Komiksowi rysownicy i scenarzyści potrafili stworzyć coś, co odbiorca mógł pojąć - czyli więcej, niż byli w stanie osiągnąć producenci ruchomych obrazów i programów radiowych" - tłumaczenie: K.C.]. Ten krótki fragment pozwala spojrzeć na motywy superbohaterskie w oderwaniu od najbardziej wiązanego z nim medium komiksu. Komiks mógł po prostu stanowić idealny środek przekazu do eksploatacji tego typu materiału, zaś kino, przez swoje ówczesne ograniczenia technologiczne, musiało ustąpić i „dojrzeć” (pod względem możliwości wizualnych) do tego, by było w stanie przyjąć „widowiskowość" i umowność tematu superbohatera. Nie zmienia to jednak tego, że film wciąż nie umożliwia tak daleko posuniętej serializacji, z jaką kojarzone są komiksy Marvela lub DC. [10] Mowa tu o teorii semantyczno-syntaktyczno-pragmatycznej, która bierze pod uwagę zarówno elementy znaczące (semantykę), sposób ich łączenia (syntaktykę), jak i zmienność 


\section{2}

wania gatunku, o których badacz wspomina w pierwszych rozdziałach swojej książki[11]. Pisze on o gatunku jako:

- strategii - wzorze, który poprzedza, ukierunkowuje i porządkuje produkcję realizowaną w ramach przemysłu filmowego;

- strukturze - ramach formalnych, na których oparte są konkretne filmy;

- etykiecie - nazwie kategorii kluczowej dla decyzji i strategii promocyjnych dystrybutorów oraz właścicieli sal kinowych;

- umowie - określonej perspektywie, jakiej od publiczności wymaga każdy gatunek.

Pozostawię na moment drugą z powyższych kategorii (by nie pisać dwa razy o tym samym formalne wyznaczniki kina superbohaterskiego zamierzam omówić w późniejszych segmentach

postrzegania tychże gatunków w historii, przez pryzmat relacji odbiorca-twórca-producent (pragmatykę). Teoria ta zostaje uznana przez Żaglewskiego za chwiejną (T. Żaglewski, Kinowe uniwersum Superbohaterów, Warszawa 2017, s. 28) w przypadku tej niszy kina, gdyż podważa ją w jego opinii obecność produkcji takich jak Kick Ass (2010), Legion samobójców (2016) czy Deadpool (2016); produkcji, które jawnie naginają „konwencję superbohaterską". W mojej opinii ich istnienie nie tyle podważa funkcjonowanie gatunku, ile nawet stanowi pewien znak jego rozwoju - o czym będę pisał w późniejszych akapitach.

[11] R. Altman Gatunki filmowe, przeł. M. Zawadzka, Warszawa, 2012, s. 53. Wymienione wyżej kategorie łączą się z perspektywą semantyczno-syntaktyczno-pragmatyczną, gdyż ma ona uwzględniać historyczne i produkcyjno-dystrybucyjno-odbiorcze uwarunkowania gatunków. [12] W 2019 roku doszło do finalizacji zakupu studia 2oth Century Fox przez Disneya, ale w chwili pisania tekstu nie powstał jeszcze film zrealizowany przez Fox pod kontrolą większego koncernu. [13] Szczególnie że większość tych strategii została porzucona (gdy mowa o wytwórniach, które zawarły umowę z Disneyem), albo właśnie ulega modyfikacji (po relatywnie chłodnym przyjęciu adaptacji komiksów DC, Warner Bros zaczęło przekształcać swoją propozycję i w tym momencie trudno ocenić, jak ewoluują kolejne tytuły $\mathrm{z}$ tego studia). Strategie te omawia Tomasz Żaglewski w Kinowym uniwersum superbohaterów. tekstu) i skupię się na aspektach produkcyjnych, dystrybucyjnych oraz relacji film-widz. W mojej opinii film superbohaterski spełnia wszystkie kategorie wymienione przez autora Gatunków filmowych. Najlepszym przykładem obrazującym realizację pierwszego aspektu gatunkowości jest sytuacja na rynku filmowym po sukcesie pierwszych produkcji młodego studia Marvela. Wnikliwi obserwatorzy kina superbohaterskiego wiedzą, że prawa do realizowania adaptacji komiksów DC comics ma Warner Bros., zaś prawa do postaci konkurencyjnego wydawnictwa zostały rozsiane po kilku różnych wytwórniach (2oth Century Fox, Sony Pictures Entertainment oraz Marvel Studios, które dziś należy do koncernu Disneya[12]). W okolicach premiery Avengers, przełomowej produkcji dla całej niszy adaptacji komiksowych, decydenci z pozostałych studiów wyczuli potencjał komercyjny mitu superbohaterskiego i postanowili skorzystać z dostępnych im zasobów, by również pójść za nasilającym się trendem. Każde studio spróbowało więc stworzyć własnych Avengers - uniwersum superbohaterów, w którym poszczególne produkcje łączyłyby się ze sobą w jedną metanarrację i tworzyły spójny świat. Każda z wytwórni podążyła nieco inną drogą, jednakże nie starczy tu miejsca na omówienie różnic między tymi wizjami[13].

Trzeci punkt widoczny jest w strategiach marketingowych dystrybutorów i producentów. Oczywiście przed seansami produkcji Marvela otrzymujemy zwiastuny filmów Marvela (samo studio wypuszcza swoje tytuły w odpowiedniej kolejności i dba o to, by promowały się nawzajem), ale da się również zauważyć koegzystencję produkcji należących do różnych wytwórni. Najbardziej namacalnym dowodem na wzajemne „wspieranie się" obrazów należących do tego samego gatunku jest współpraca studia Sony z 2oth Century Fox w 2014 roku - mowa tutaj o zamieszczeniu sceny z X-Men: Days of Future Past w trakcie napisów do Niesamowitego Spider-Mana 2. Fabuły, światy i postacie tych opowieści filmowych nie krzyżują się, jednak specjaliści od marketingu wiedzieli, że osoby zainteresowane jedną z nich, chętniej pójdą na drugą. 
„Gatunek superbohaterski” funkcjonuje jako umowa - widownia wyrobiła sobie po latach oglądania filmów superbohaterskich konkretne oczekiwania, zaś twórcy coraz odważniej wplatają elementy charakterystyczne dla oryginalnych historii (które wcześniej mogłyby zostać odrzucone), wierząc, że odbiorcy je przyjmą. Minął już ten czas, gdy w latach dziewięćdziesiątych kino superbohaterskie kojarzyło się masowej widowni $\mathrm{z}$ absolutnym kiczem; minął też czas pierwszej dekady XXI wieku, gdy produkcje opowiadające o superherosach raczej wstydziły się swojej komiksowości[14]. Twórcy wiedzą też, że reguły fabuły superbohaterskiej są doskonale znane współczesnym widzom, dlatego też starają się odpowiednio modyfikować schematy kolejnych filmów (przy zachowaniu znajomych motywów).

\section{Wyznaczniki formalne}

\section{"filmu superbohaterskiego"}

Przejdę teraz do drugiego punktu z ustaleń Altmana oraz analizy gatunkowości kina superbohaterskiego. Od strony scenariuszowej filmy te cechuje pewien wspólny schemat. Niemal każda opowieść z tego gatunku opiera się na bohaterach posiadających fantastyczne zdolności. Mogą być wrodzone, jak w przypadku Supermana (tetralogia Superman, Superman: Powrót, Man of Steel), Iniemamocnych (Iniemamocni) czy X-Men (seria X-Men); nabyte - jak w przypadku Spider-Mana (na przykład trylogia Spider-Man Sama Raimiego) czy Shazama (Shazam!, 2019, reż. David F. Sandberg), uzyskane dzięki konkretnym artefaktom - jak u Zielonej Latarni (Zielona Latarnia, 2011, reż. Martin Campbell) czy drużyny Power Rangers (seriale i film Power Rangers); bądź uzyskane dzięki wiedzy i technologii, jak w przypadku Iron Mana (trylogia Iron Man, tetralogia Avengers). Istnieją także postacie, które nie dysponują umiejętnościami wykraczającymi poza ludzkie możliwości - cechują się niezwykłą sprawnością fizyczną czy inteligencją, jak Batman (na przykład tetralogia Batman z lat dziewięćdziesiątych). Wciąż ich umiejętności stanowią element fantazji i wynoszą bohaterów ponad zwykłych śmiertelników, ale w obrębie reguł świata przedstawionego pochodzić mają wyłącznie z potencjału ludzkiego ciała.

Bohaterowie postanawiają wykorzystać swoje zdolności, by działać w służbie dobra lub przeciwko złu. W zależności od postaci możemy mieć różne postawy moralne: od najbardziej standardowych, konwencjonalnych, szlachetnych bohaterów (na przykład Superman, Spider-Man), po tych, których możemy uznać za dekonstrukcję postaci superbohatera (jak Punisher czy Deadpool, którzy nie mają oporów przed zabijaniem przestępców, w przeciwieństwie do pozostałych herosów). Opowieści superbohaterskie charakteryzuje także dualizm świata - na protagonistów niemal zawsze czeka antagonista. Pełni on mniejszą lub większą rolę - czasem stawiany jest jako opozycja ideowa wobec wartości wyznawanych przez bohatera. Przykładowo Tony Stark pragnie zmienić profil swojego przedsiębiorstwa, by nie czerpać zysków z wojny, zaś Obadiah Stane chce sprzedawać broń terrorystom, by skapitalizować cierpienie niewinnych (Iron Man); T'Challa pragnie bezkonfliktowo wspomagać mniejszość afroamerykańską, zaś jego antagonista Killmonger dąży do odwrócenia kolonialnej historii i krwawej zemsty na białych (Czarna Pantera, 2018, reż. Ryan Coogler); Batman reprezentuje porządek, a Joker chaos (Mroczny rycerz, 2008, reż. Christopher Nolan). Czasem przeciwnik stanowi lustrzane, negatywne odbicie charakteru protagonisty (wspomniani wyżej Batman i Joker), a czasem gra jedynie rolę pewnej przeszkody do pokonania i nie okazuje się faktycznym czarnym charakterem [z pozoru złowroga postać grana przez Hannah John-Kamen w Ant-Manie i Osie (2017, reż. Pey-

[14] Znamienny może być $\mathrm{w}$ tym przypadku autotematyczny komentarz w filmie $X-M e n$ $\mathrm{z} 2000$ roku, w którym to jedna z postaci wyśmiewa perspektywę noszenia kolorowych spandeksów (w komiksowym odpowiedniku postacie te korzystają z jaskrawych, wielobarwnych kostiumów). Dziś twórcy filmów nie mają problemu z ubieraniem bohaterów w kiczowate, obcisłe kombinezony. 
ton Reed) zostaje „zrehabilitowana” w ostatnich sekwencjach historii, gdyż dowiadujemy się, że to skrzywdzona przez eksperyment dziewczyna, która pragnie powrócić do normalnego życia]. Obecność złoczyńcy lub domniemanego złoczyńcy jest jednak nieodłącznym elementem dramaturgii produkcji superbohaterskiej, gdyż to właśnie działania innej „super-siły” często napędzają fabułę filmu superbohaterskiego i zmuszają herosa do działania.

Niemal zawsze akcja rozgrywa się w świecie fantastycznym, nawet jeśli fantastyczne są tylko pewne jego drobne elementy (także $\mathrm{w}$ adaptacjach losów Batmana autorstwa Christophera Nolana, który starał się osadzić opowieść w realistycznej stylistyce, można odnaleźć technologię wziętą rodem z science fiction). Jednakże zazwyczaj te historie rozgrywają się w rzeczywistości przypominającej nasz współczesny świat ewentualnie w rzeczywistości XX wieku lub niedalekiej przyszłości. Zespolenie superbohaterów ze współczesnością to niezwykle ważny wątek, bowiem zarówno ich geneza bardzo często odwołuje się do tematów charakterystycznych dla najnowszej nauki oraz jej daleko idących przetworzeń w science fiction (w postaci eksperymentów genetycznych, mutacji, transhumanistycznych usprawnień ludzkiego ciała), jak i motywy poruszane w produkcjach odwołują się do problemów dzisiejszego świata (alegoria mniejszości seksualnych/etnicznych w X-Men, konflikty zbrojne na Bliskim Wschodzie w Iron Manie, napięcia rasowe w Czarnej Panterze).

[15] Oczywiście mowa tutaj o pewnym podstawowym łączniku. Jeśli zagłębimy się w historie superbohaterskie, będziemy mogli odnaleźć inne cechy charakterystyczne dla tego gatunku. Na przykład w postkolonialnej interpretacji Chrisa Gavalera jednym z elementów mitu superbohaterskiego jest jego związek z motywami imperialnymi/kolonialnymi. Choć pisze on głównie o prototypach postaci superbohaterów i problematycznych genezach/historiach postaci z lat sześćdziesiątych, wskazuje on na to, że motywy kolonialne odbijają się echem także we współczesnych interpretacjach (na przykład filmowych). Jest to wątek, który warto rozważyć, bowiem superbohater w specyficzny sposób
Nawet jeśli tworzywem postaci i powiązanych $\mathrm{z}$ nią motywów jest fantasy, zestawiona zostaje ona ze współczesnym światem (przykładowo Doktor Strange to czarodziej stacjonujący w dzisiejszym Nowym Jorku, zaś Thor, kosmita - inspirowany nordyckim bóstwem - przywiązany jest do współczesnej Ziemi i w każdym swoim filmie na niej się pojawia).

Bohaterom kina superbohaterskiego towarzyszy także charakterystyczna ikonografia i motywy przewodnie. Są oni zakotwiczeni w „komiksowości” - bo choć różnią się statusem społecznym, charakterem, wyglądem czy ideologią, mają pewne podobne elementy, które od razu budują skojarzenie z całą niszą superbohaterskich opowieści i mocno opierają się na wizualności. „Składniki” herosa, które przewijają się w wielu historiach z tej kategorii, to pseudonimy, ukryte tożsamości, podwójne życia, kostiumy, supermoce, samotna lub grupowa walka z przestępczością. Rzecz jasna nie każdy bohater może spełniać wszystkie te warunki - podczas gdy Spider-Man czy Superman (czyli jedni z najpopularniejszych superbohaterów) faktycznie związani są z każdym wymienionym wyżej elementem, reszta postaci może być któregoś z nich pozbawiona.

Kino superbohaterskie nie wykształciło natomiast spójnej estetyki czy stylistyki (która w jednoznaczny sposób oddzieliłaby je od reszty filmów akcji), choć pewne elementy wspólne - jak monumentalizm, wyzwolenie kamery czy dynamizm montażu - występują w większości produkcji. Estetycznie filmy superbohaterskie mogłoby też wyróżnić skupienie na komiksowej ikonografii - co znów mogłoby jednak świadczyć o tym, że filmy superbohaterskie to specyficzny podgatunek kina akcji. Podobne schematy fabularne i konwencje przedstawieniowe można znaleźć w niezliczonych produkcjach kina rozrywkowego, łącznie z obligatoryjną, kulminacyjną sceną akcji w finale. Gdy spojrzymy jednak na to, w jakie modele łączą się wymienione w poprzednich akapitach motywy (czyli przejdziemy od aspektu semantycznego do syntaktycznego), będziemy mogli wyciągnąć jeden motyw[15] przewijający się 
przez większość (jeśli nie wszystkie) opowieści o superbohaterach. Motyw ów opiera się na zależności między bohaterem, jego mocą a otaczającą go „społecznością (albo też - słowami mentora jednego z marvelowskich bohaterów między mocą a odpowiedzialnością). Zależność ta opiera się na napięciu powstałym $\mathrm{z}$ wyboru etycznego dotyczącego sposobu wykorzystywania umiejętności. W najbardziej standardowym schemacie bohater uczy się, by wykorzystywać swoje niezwykłe zdolności w służbie dobra. Mogą nimi być nabyta/wrodzona moc, zasoby techniczne/finansowe, fizyczne atrybuty. Ważne jest to, że wykorzystanie tych zdolności odbywa się zazwyczaj poza jurysdykcją władzy (bohater stanowi samodzielną „instytucję”), a czasem i na granicy prawa. Istnieją, rzecz jasna, odstępstwa od tej reguły albo próby stematyzowania dylematu: „co wolno superbohaterowi?”[16].

\section{Ewolucja formuły gatunkowej}

Ważną kwestią przy omawianiu formuły gatunkowej „filmów superbohaterskich” jest jej ewolucja. Gatunki nie ewoluują, rzecz jasna, w przewidywalny sposób, ale w historii kinowych opowieści o superherosach można dostrzec ciągły rozwój formuł i konwencji z nimi związanych. Oczywiście, jak pisze Żaglewski, serie adaptacji komiksów Marvela i DC w ostatnich latach zmierzają w stronę połączonych struktur uniwersalnych - choć jak najbardziej nie powinno zapominać się o tej kwestii przy omawianiu rozwoju tego działu kina, warto mieć na uwadze także rozwój formuły wewnątrz opowieści, niezależnie od ich stopnia powiązania $z$ innymi tytułami. W ostatnich latach pojawia się coraz więcej filmów przełamujących standardowe schematy związane $\mathrm{z}$ tego typu produkcjami.

Trudno określić jednak rozwój formuły superbohaterskiej mianem linearnego. Za pierwszą pełnoprawną, pełnometrażową adaptacją opowieści o superbohaterze (zapisaną w kodzie "gatunku”), która przeszła do kanonu tej kategorii kina, można uznać produkcję Superman Richarda Donnera z 1978 roku. Stanowi bardzo proste przeniesienie najważniejszych motywów historii tytułowego superbohatera i można by go uznać za pewną prototypową opowieść. Z jednej strony mamy ratującego lu-

reprezentuje siłę i pomaga utrzymać status quo świata przedstawionego, a ponadto kulturowo powiązany jest ze Stanami Zjednoczonymi (tam się narodził i w tamtej przestrzeni funkcjonuje). W dodatku do amerykańskiej drużyny dołączają często postacie pochodzące $\mathrm{z}$ innych krajów (fikcyjnych bądź prawdziwych), które razem z zachodnią drużyną budują światowy ład. Wątek władzy dzierżonej przez superbohaterów zostaje poruszony w niektórych produkcjach - na przykład w Avengers: Era Ultrona w którym to zagraniczne działania superbohaterów przypominają antyterrorystyczne ingerencje amerykańskiego wojska, albo Kapitan Ameryka: Wojna bohaterów, gdzie postawione zostaje pytanie: kto powinien sprawować nadzór nad działaniami superbohaterów? (C. Gavaler, The imperial superhero, „PS: Political Science and Politics” 2014, vol. 47, nr 1, s. 108-111).

[16] David Hymen wskazuje na dość istotny wyróżnik gatunku superbohaterskiego w obrębie komiksu - skłonność do nieustannego rewizjonizmu, nadpisywania poprzednich tekstów przez kolejne „odcinki” historii. Trudno jednak przenieść ten element na grunt filmu - podczas gdy komiksowy Tony Stark/Iron Man funkcjonuje w komiksach od lat sześćdziesiątych i stale kontynuuje swoją wędrówkę, starzejąc się najwyżej o kilka lat (czas w komiksie jest elastyczny właśnie dzięki wspomnianemu rewizjonizmowi: liczy się tekst późniejszy i w ten sposób geneza Iron Mana - jego pierwsza historia - choć pierwotnie miała miejsce podczas wojny w Wietnamie, to dziś umiejscawiana jest $\mathrm{w}$ Afganistanie, a jednak zeszyty związane $\mathrm{z}$ tą postacią umownie traktuje się jak ciągłą serię), filmowy Tony Stark jak najbardziej podlega naturalnemu procesowi starzenia się - przepracował kompleks dotyczący jego ojca i później sam pełnił rolę figury ojcowskiej, a w końcu został też ostatecznie uśmiercony. Bohater komiksu dzięki specyfice medium może być zawsze młody, zaś postać filmowa wydaje się wrażliwa na upływ czasu - nie tylko dlatego, że sami aktorzy podlegają procesowi starzenia. Twórcy serii filmów Marvela, choć przybliżają ją formatem do serialu, wciąż starają się traktować większość swoich produkcji jak pojedyncze, zamknięte historie, zaś śmierć oraz ostateczny koniec pojawiają się częściej niż w przypadku 
dzi protagonistę, korzystającego z supermocy i specyficznej symboliki, konkretnego antagonistę z nadludzkimi możliwościami (intelekt/

oryginalnych opowieści (D. Hyman, Revision and the Superhero Genre, New York 2017).

[17] "One of the reasons why superhero movies have been appealing for audiences is because they're fantastical, escapist metaphors for $9 / 11$ without even addressing it as an actual historical event. Viewers don't really want to relieve that horrible day - it is still too close, too traumatic. [...] But as an emotional and psychological condition experienced at a massive cultural level, our society needs a stories to help us understand and deal with the effects on terror. [...] As James N. Gilmore argues: «The superhero film, then, continues to replay a collective urban trauma, a cultural memory transformed into an uneasy spectacle». In the Dark Knight Trilogy Batman narrowly saves Gotham City from being destroyed by R'as Al Ghul, then the Joker, and finally from Bane and Talia al Ghul. Spider-man saves New York from Doctor Octopus' mega-bomb. Captain America sacrifices himself to keep a Nazi/Hydra plane loaded with bombs from crashing into New York. [...] The metaphor is not very complex: the cities may be different but they all represent New York, the heroes all represent a personification of the American spirit and they always defeat the bad guys and save the city. There may be damage, the hero may be wounded, but at the end of the day the superhero and America are still standing." („Jednym z powodów, dlaczego filmy superbohaterskie przypadły do gustu publiczności, jest to, że stanowią eskapistyczną, fantastyczną metaforę tragedii 11.09 bez wspominania faktycznego, historycznego wydarzenia. Widzowie nie chcą tak naprawdę przeżywać na nowo tego okropnego dnia - wydarzył się niedawno i jest zbyt traumatyczny. [...] Jednakże, $z$ uwagi na emocjonalny i psychologiczny stan, odczuwany na masowym, kulturowym poziomie, nasze społeczeństwo potrzebuje historii, które pomogą nam zrozumieć i poradzić sobie ze skutkami terroru. [...] Jak twierdzi James N. Gilmore: «Film superbohaterski kontynuuje powtarzanie zbiorowej, miejskiej traumy, przetwarza kulturową pamięć na niespokojny spektakl». W trylogii Mrocznego rycerza Batman $\mathrm{z}$ trudem ratuje miasto Gotham od zniszczenia przez R'as Al Ghula, później Jokera i ostatecznie Bane’a oraz Talię Al Ghul. Spider-Man ratuje Nowy Jork przed bogactwo), a także wspomniane napięcie między bohaterem, jego mocą a społeczeństwem. Za inną prototypową opowieść - stanowiącą raczej wzór autorskiego podejścia do materiału źródłowego - można uznać dwie adaptacje losów Batmana z 1989 i 1991 roku, w reżyserii Tima Bartona (Batman i Powrót Batmana). W czasie premiery pstrokatych, barokowych i bardziej komediowych realizacji autorstwa Joela Schumachera (Batman Forever z 1995, Batman \& Robin z 1996) mogło się wydawać, że kino superbohaterskie zmierza ku wyczerpaniu - w pierwszej dekadzie XXI wieku nastąpił jednak przełom, na który wpływ mogło mieć pragnienie eskapistycznego przepracowania społecznych traum po 11 listopada 2001 roku[17], a także rozwój technologiczny kina. Nowatorskie okazały się dwie adaptacje - X-Men Bryana Singera z 2000 roku oraz Spider-Man[18] Sama Raimiego. Drugi film stanowi bardziej klasyczną opowieść z gatunku, pierwszy zaś wprowadza antybohatera (Wolverine'a - który jednak zmienia się z czasem w bohatera), a także zespół superbohaterski. Po sukcesach sequeli obu produkcji, a także wielu nieudanych próbach naśladownictwa, znów mogłoby się wydawać, że formuła została wyczerpana, jednakże produkcje Christophera Nolana (Batman Początek, Mroczny Rycerz, Mroczny Rycerz powstaje) oraz narodziny Marvel Cinematic Universe sprawiły, że rozpoczął się nowy okres w historii gatunku. Od premiery filmu Avengers, wieńczącego fabuły pierwszych produkcji studia Marvela, także inne wytwórnie zaczęły tworzyć ze swoich zasobów łączone światy; nieco bardziej złożone narracje, planowane kilka lat naprzód.

W tym czasie pojawiło się coraz więcej realizacji przełamujących schematy - Logan wprowadził temat ostatecznego końca (zarówno z perspektywy widza, jak i świata przedstawionego) „nieśmiertelnego” bohatera. Deadpool stanowi parodię i komentarz do współczesnych produkcji superpbohaterskich studia Marvela, Foxa i Warner Bros. Formalny charakter opowieści z „głównego nurtu” również wydaje się rozwijać - Kapitan Ameryka: Wojna bohaterów stawia w centrum konflikt między superboha- 
terami, a nie, jak w klasycznej formule, przedstawicielami dobra i zła. Shazam! podejmuje temat wejścia $\mathrm{w}$ rolę superherosa przez nastolatka, którego mentorem zostaje jego rówieśnik (jako że motywy superbohaterskie stanowią część świata przedstawionego oraz element popkulturowego kodu, na którym młodzi bohaterowie zostali wychowani, podchodzą oni do niezwykłej mocy z perspektywy „fanów” niszy).

Kino superbohaterskie nigdy wcześniej nie opierało się w takim stopniu na grze konwencjami gatunkowymi, jak w ubiegłej dekadzie gatunki przejawiają swoją funkcję w połączeniu z serialowością Marvel Cinematic Universe. Producenci i twórcy szukają dla poszczególnych protagonistów odpowiednich formuł - i tak Ant-Man (2015, reż. Peyton Reed), film opowiadający o włamywaczu, dostał formułę heist movie wymieszaną z elementami produkcji familijnej, Spider-Man: Powrót do domu (2017, reż. Jon Watts) z nastoletnim protagonistą czerpie wiele elementów $\mathrm{z}$ filmów młodzieżowych (na przykład obligatoryjną scenę ze szkolną potańcówką czy konkretne typy postaci, takie jak „bully” znęcający się nad niepopularnym w szkole protagonistą), zaś Kapitan Ameryka: Zimowy żołnierz (2014, reż. Anthony Russo, Joe Russo) to tytuł, który można porównać z thrillerami szpiegowskimi/politycznymi. Nic dziwnego, że filmy superbohaterskie wchodzą $\mathrm{w}$ mariaż z innymi gatunkami - mieszanie konwencji pozwala na zróżnicowanie portfolio studia, opowiedzenie historii zamaskowanego mściciela w inny sposób, a także na odnalezienie nowych widzów. W tym momencie można zadać sobie pytanie: na ile te produkcje można zaliczyć do proponowanego przeze mnie "gatunku superbohaterskiego", a na ile są one zdominowane przez inne konwencje? Sądzę, że decydujące mogą być tu takie kwestie jak skupienie na postaci superbohatera (podkreślone już przez samy tytuł - na przykład Ant-man) oraz marketing, który raczej uwypukla fakt, że w centrum opowieści znajduje się figura współczesnego herosa. Niezależnie od tego, czy mowa o Ant-Manie czy Kapitanie Ameryce: Zimowym żołnierzu, można założyć, że to jednak „super- bohaterskość" głównych postaci stanowi dominantę opowieści (oraz główny element, z którym widzowie identyfikują daną produkcję).

Co natomiast zrobić $\mathrm{z}$ utworami jawnie naginającymi konwencję? Żaglewski wymienia między innymi Legion samobójców (2016, reż. David Ayer) oraz Deadpoola (2016, reż. Tim Miller) jako kontrargument dla "gatunkowego" charakteru kina superbohaterskiego. Wspomniane opowieści stawiają $\mathrm{w}$ centrum postacie przełamujące schematy, a za cel satyry biorą elementy kina superbohaterskiego (Legion samobójców opowiada o grupie złoczyńców, zaś tytułowy Deadpool otwarcie komentuje zarówno swój film, jak i pozostałe adaptacje komiksów). Ja jednak uznałbym występowanie subwersji za wynik rozwoju gatunku superbohaterskiego i poszukiwania przez twórców oraz producentów innego spojrzenia na formuły do tej pory eksploatowane (istnienie wymienionych pastiszów/parodii stanowi odpowiedź na regularne funkcjonowanie $\mathrm{w}$ obrębie kina superbohaterskiego konkretnych, stałych elementów i schematów gatunkowych, które to wspomniane produkcje próbują odwrócić czy wyśmiać). Motywy kina superbohaterskiego na tyle wrosły w świadomość odbiorców, że jedynym sposobem na zapewnienie jego przetrwa-

megabombą Doktora Octopusa. Kapitan Ameryka poświęca siebie, by powstrzymać wypełniony ładunkami wybuchowymi samolot Nazistów/ Hydry od uderzenia w Nowy Jork [...] Metafora nie jest zbyt skomplikowana: możemy mieć do czynienia z różnymi miastami, ale wszystkie reprezentują Nowy Jork, bohaterowie reprezentują zaś amerykańskiego ducha i zawsze pokonają złoczyńców oraz uratują miasto. Mogą zdarzyć się uszkodzenia, bohater może ucierpieć, ale na końcu dnia zarówno superbohater, jak i Ameryka, stoją na nogach (J.A. Brown, The Modern Superhero in Film and Television. Popular Genre and American Culture, Routledge, New York, London, 2017, s. 64-66, tłum. K.C.).

[18] Wcześniej powstał także Blade: Wieczny łowca (1999, reż. Stephen Norrington), jednakże tej produkcji nie zaliczałbym do gatunku superbohaterskiego, bo i samego protagonistę (łowcę wampirów) trudno uznać za superbohatera. 
nia jest rozwój. Czasem ewolucja ta przebiega w obrębie opowieści podchodzących do swoich motywów „na serio” (wspomniany przykład Kapitana Ameryki: Wojny Bohaterów), czasem zaś wiąże się z powstawaniem pastiszów i parodii, biorących pod lupę wypracowane motywy. W dodatku trudno powiedzieć, na ile odważną czy znaczącą kontrpropozycję dla innych produkcji stanowi Legion samobójców, gdyż pomimo swojego prześmiewczego/buntowniczego charakteru pod względem struktury fabularnej, budowy świata i postaci nie odchodzi aż tak daleko od swoich konwencjonalnych „pobratymców”. Być może to w przypadku Deadpoola można mówić o wyrazistym przesunięciu (opiera się ono na postaci, która jest świadoma swojej fikcyjności i regularnie przełamuje czwartą ścianę oraz reguły „etosu superbohaterskiego”). W kontekście koncepcji Altmana warto jednak wspomnieć też, że zarówno twórcy, jak i autorzy kampanii marketingowych świadomie traktowali i reklamowali te filmy jako produkcje odchodzące od standardowych motywów superbohaterskich - a nie typowego przedstawiciela gatunku. Buntowniczość, a więc wyjście poza schematy gatunku, stanowić miała wartość tych tytułów. Trudno więc uznać je za tę samą kategorię produkcji - nawet jeśli współdzielą światy z konwencjonalnymi odpowiednikami, nie stanowią klasycznych przypadków swojego gatunku, lecz - pod pewnymi względami - odwrócenie jego reguł.

$\mathrm{Na}$ zakończenie tego tekstu chciałbym zaznaczyć, że moja propozycja nie polega na zupełnym oderwaniu kina superbohaterskiego od komiksowych korzeni, czy nawet komiksowego sposobu opowiadania. Byłbym raczej skłonny traktować je jak gatunek filmowy, który poddaje przekształceniu gatunek wypracowany w medium komiksu. Należy również pamiętać, że postrzeganie kina superbohaterskiego wciąż się zmienia, tak jak ono samo nieustannie ewoluuje. Zapewne dopiero z czasem będzie moż- na dokonać pełniejszej, bardziej pogłębionej analizy tego zjawiska ( $\mathrm{z}$ uwzględnieniem jego dalszego rozwoju). Trudno dać jednoznaczną odpowiedź na pytanie: jak kino superbohaterskie będzie wyglądać za kilka lat?, bowiem niedawno zmienił się układ sił w obrębie wielkich wytwórni, a niektóre strategie wprowadzania kolejnych adaptacji komiksów uległy przekształceniu (część zapowiedzianych przez producentów filmów długo nie ujrzała światła dziennego - warto przywołać przypadek The New Mutants, produkcji, która w 2017 roku dostała pierwszy zwiastun, ale od tamtego czasu data jej premiery była kilkukrotnie przekładana, aż do sierpnia 2020 roku). Marvel Studios, wraz z premierą Avengers: Koniec gry (2019, reż. Anthony Russo, Joe Russo) zakończyło jedenastoletnią „sagę” poświęconą bohaterom swoich pierwszych produkcji i utrzymało się bez negatywnych konsekwencji, ale nawet gdy wkroczy z nowymi koncepcjami w kolejnych latach, trudno będzie przewidzieć, w jaką stronę podążą przyszłe tytuły - a zatem kierunek rozwoju całego gatunku pozostaje w tym momencie do pewnego stopnia niewiadomą.

B I B L I O G R A F I A

Altman R., Gatunki filmowe, przeł. M. Zawadzka, Warszawa 2012

Brown J.A., The Modern Superhero in Film and Television. Popular Genre and American Culture, Routledge, New York, London 2017

Gavaler C., The Imperial Superhero, „PS: Political Science and Politics" vol. 47, nr 1, Cambridge 2014

Hyman D., Revision and the Superhero Genre, New York 2017

Jeffries D., Comic Book Film Style, Austin 2017

Satrapi M., Persepolis, przeł. W. Nowicki, Warszawa 2015

Waid M., Ross A., Kingdom Come - Przyjdź królestwo, przeł. M. Drewnowski, Warszawa 2005

Żaglewski T., Kinowe uniwersum superbohaterów, Warszawa 2017 